\title{
UM ESTUDO SOBRE LABORATÓRIOS MULTIDISCIPLINARES DE CIÊNCIAS DA NATUREZA EM ESCOLAS PÚBLICAS DA REGIÃO OESTE DO PARÁ
}

\author{
Ademir de Souza Pereira ${ }^{1}$ \\ Naicy Camila Paixão da Conceição²
}

\section{RESUMO}

Por meio da presente pesquisa, analisamos a implantação e a utilização de vinte laboratórios didáticos multidisciplinares de Ciências da Natureza, situados em cinco municípios da região Oeste do Pará. Foram visitadas vinte e seis escolas, localizadas em sete municípios distintos, entre os anos de 2012 e 2016. Dezoito professores que atuam nos laboratórios didáticos responderam a um questionário e submeteram-se a uma entrevista semiestruturada. Estas foram organizadas em torno dos processos de implantação dos laboratórios e suas estruturas, das formações dos professores e das atuações nos laboratórios. Constatamos que a escolha para a implantação dos laboratórios não ocorreu no contexto da escola e que a maioria dos professores atuantes nos espaços não se sentiu confiantes em desenvolver sua atividade, haja vista que durante as formações básicas não houve formação para atuação com o uso da experimentação didática. A partir destas constatações, sugerimos que abordagens sobre laboratórios multidisciplinares em Ciências da Natureza sejam curricularizadas nos cursos de formação de professores e que os professores atuantes sejam oportunizados a frequentar espaços formativos que contemplem abordagens sobre os laboratórios didáticos multidisciplinares.

Palavras-chave: Laboratório multidisciplinar didático. Experimentação didática. Pesquisa qualitativa.

\section{A STUDY ON MULTIDISCIPLINARY LABORATORIES OF NATURE SCIENCES IN PUBLIC SCHOOLS IN WESTERN PARÁ}

\footnotetext{
1 Possui graduação em Licenciatura em Química, Mestre em Ensino de Ciências/Ensino de Química pela Universidade Federal do Mato Grosso do Sul (UFMS) e Doutor em Educação para a Ciência pelo Programa de Pós-graduação em Educação para a Ciência da Universidade Estadual Paulista "Júlio de Mesquita Filho" (UNESP), Professor do curso de Licenciatura em Química da Faculdade de Ciências Exatas e Tecnologias da Universidade Federal da Grande Dourados (UFGD). Orcid iD: https://orcid.org/0000-0002-3635-7349 E-mail: ademirpereira@ufgd.edu.br

2 Licenciada em Ciências Biológicas, pela Universidade Federal do Oeste do Pará (UFOPA). Pós-graduanda em Ensino de Ciências e Matemática em IFPA - Instituto Federal do Pará. Orcid iD: https://orcid.org/0000-0001-8109-5010. E-mail: camila_ncgp@hotmail.com
} 


\section{ABSTRACT}

Through the present research, we analyzed the implantation and use of twenty multidisciplinary didactic laboratories of Natural Sciences, located in seven municipalities of the western region of Pará. Twenty-six schools that was located in seven distinct municipalities between the years of 2012 and 2016. Eighteen teachers that act in the didactic laboratories answered a questionnaire and underwent a semi-structured interview. These were organized around the processes of implantation of the laboratories and their structures, of the formations of the professors and performances in the laboratories. We found that the choice for the implantation of the laboratories did not occur in the context of the school and that most of the teachers working in the spaces that they did not feel confident in carrying out their activities, since during the basic training they did not have the training to experiment didactic Based on these findings, we suggest that approaches to multidisciplinary laboratories in Natural Sciences be curricularized in the courses of training of science teachers and that the active teachers are given the opportunity to attend formative spaces that contemplate approaches on didactic laboratories.

Keywords: Didactic multidisciplinary laboratory. Didactic experimentation. Qualitative research.

\section{UN ESTUDIO SOBRE LOS LABORATORIOS MULTIDISCIPLINARES DE LAS CIENCIAS NATURALES EN ESCUELAS PÚBLICAS DE LA REGIÓN OESTE DEL PARÁ}

\section{RESUMEN}

Através da presente pesquisa, hay un análisis de implantación y el uso de veinte laboratorios didácticos multidisciplinares de Ciencias de la Naturaleza, en cinco municipios da região Oeste do Pará. Se visitaron veintiséis escuelas, ubicadas en siete municipios distintos, entre los años 2012 y 2016 . Dieciocho profesores que trabajan en los laboratorios didácticos respondieron a un cuestionario y se sometieron a una entrevista semiestructurada. Estas formaciones fueron organizadas en torno a los procesos de implantación de los laboratorios de trabajo y sus estructuras, las formaciones de los profesores y los centros de atención son las actividades y los laboratorios. Consta un plan de trabajo para la implementación de los laboratorios no ocurrió en el contexto de la escuela y que la mayoría de los expertos actuantes en los espacios no se sintió confiados en desarrollar su actividad, ya que durante las formaciones básicas no hubo formación para actuación con el uso de la experimentación didáctica. A partir de estas constataciones, sugerimos que abordemos sobre laboratorios multidisciplinares en ciencias de la naturaleza sean curricularizados en los cursos de formación de profesores de ciencias y que los profesores actuantes sean oportunizados a frecuentar espacios formativos que contemplen sobre los laboratorios didácticos.

Palavras clave: Laboratório multidisciplinar didático. Experimentação didática. Pesquisa cualitativa. 


\section{INTRODUÇÃO}

Em 2001, o Governo Federal, por meio do Ministério da Assistência e Promoção Social (MAPS), lançou o Projeto Alvorada - Decreto n 3.769, de 8 de março de 2001 - visando intensificar ações que tivessem impacto na melhoria das condições de vida da população de Estados brasileiros ${ }^{3}$ que apresentavam baixo Índice de Desenvolvimento Humano (IDH), investindo recursos na área da educação, saúde e geração de renda. Com o apoio de gestores nos Estados e Municípios, esperavam contribuir para a redução da desigualdade social de parte da população, inclusive, por meio de apoio à Educação Básica.

Conforme Menezes (2001), na área de educação, o Projeto Alvorada centralizou-se no repasse de verbas para diversos programas direcionados ao Ensino Fundamental, ao Ensino Médio e à educação de jovens e adultos, como o Bolsa-Escola e o Programa Desenvolvimento do Ensino Médio.

Com a mediação da Secretaria Estadual de Educação do Estado do Pará (SEDUC), uma das metas do Projeto Alvorada foi o apoio ao ensino de Ciências da Natureza, nos níveis fundamental e médio, por meio da implantação de laboratórios multidisciplinares (LMD) em escolas; as quais receberam kits para experimentação didática, equipamentos de uso permanente e construção ou adequação do espaço físico (PAIXÃO; PEREIRA, 2012).

Antes de iniciar o funcionamento dos LMD, a SEDUC ofereceu um curso de aperfeiçoamento para professores do nível médio de ensino, atuantes nas áreas de Ciências da Natureza e Matemática - convênio 082/2002Projeto Alvorada. Outro curso de aperfeiçoamento foi realizado por meio do convênio MEC/SEMTEC/SEDUC 1651/2006, firmado entre a SEDUC e o Núcleo Pedagógico de Apoio ao Desenvolvimento Científico (NPADC) da Universidade Federal do Pará (UFPA).

Diante desse contexto, a Secretaria Estadual de Educação do Pará (SEDUC-PA), organizou a estrutura administrativa e pedagógica na escola

3Foram contemplados os seguintes Estados: Pará, Rondônia, Roraima, Alagoas, Bahia, Ceará, Maranhão, Paraíba, Pernambuco, Piauí, Rio Grande do Norte, Sergipe e Tocantins. 
para que professores assumissem a função de professor do laboratório multidisciplinar conforme a portaria n. 23/2011 da SEDUC/PA, artigo 11:

Art. 11 - A lotação de professores e Programas e Projetos, previstos no Projeto Político Pedagógico de cada Escola, deverá obedecer aos seguintes critérios: I - Possuir habilitação correspondente à natureza do ambiente e do programa ou projeto, mediante análise e autorização da SAEN; II - Apresentar documento comprobatório de participação nos cursos promovidos pelos NTE's da SEDUC, para lotação de professores nos Laboratórios de Informática; III Apresentar documento comprobatório de participação em cursos de capacitação, para a lotação de professores nos Laboratórios Multidisciplinares da SEDUC; IV - Será lotado um professor por turno [...] devendo apresentar um Plano de Ação integrado ao Projeto Político Pedagógico da escola, devidamente autorizado pela SAEN. (SEDUC, 2011, p.10).

A Portaria $n^{\circ}$ 617/2012 da SEDUC-PA, em seu inciso 12 acrescenta que o professor deverá possuir habilitação correspondente à natureza do ambiente e do projeto. Nesse contexto, O LMD é reconhecido como um espaço pedagógico e a lotação de professores deverá seguir critérios estabelecidos na Instrução Normativa n ${ }^{\circ} 3$ de 1 março de 2016:

Art. $8^{\circ}$ A lotação nos Espaços Pedagógicos (laboratórios de informática, bibliotecas escolares, salas de leituras e laboratórios multidisciplinares) previstos no Projeto Político Pedagógico de cada escola, somente ocorrerá ao professor que exercer carga horária em regência de classe, com jornada de 20 (vinte) horas semanais de regência, sendo 04 (quatro) horas diárias ininterruptas, acrescida das horas-atividades a ela correspondente, com as vantagens do magistério, para um período de até 12 (doze) meses, dentro do ano letivo em curso, cumprindo-se os 200 (duzentos) dias letivos, e incluir, obrigatoriamente, os projetos e demais documentos exigidos no Sistema de Acompanhamento de Projetos Pedagógicos (SAPP) para efeito de aprovação.

[...] § $3^{\circ}$ A lotação no espaço Laboratório Multidisciplinar só poderá ser efetivada para professores licenciados em Biologia, Química, Física ou Matemática condicionado ao efetivo funcionamento do espaço e apresentação de relatório trimestral devidamente postado no SAPP com validação da direção da escola (SEDUC/PA, 2016, p.41).

Além disso, o docente interessado deverá elaborar, previamente, um plano de trabalho no qual conste as atividades que serão desenvolvidas nesse espaço pedagógico. 
De acordo com Brasil (2018), as escolas do Ensino Médio apresentam os seguintes valores a respeito da existência de laboratórios de ciências: $81,3 \%$ das escolas federais possuem laboratório dentro do total de 552 escolas existentes. Esse número cai para $28,2 \%$ das escolas municipais que possuem esse espaço. Já $58,3 \%$ das escolas privadas possuem laboratório de Ciências, e 39,2\% das escolas de Ensino Médio estaduais possuem laboratório. No Brasil, a rede estadual é responsável pelo maior número de escolas de Ensino Médio. 68,2\% delas pertencem a essa rede, seguidas da rede privada com $29,0 \%$ das escolas (BRASIL, 2018).

Os números acima apontam para a necessidade de averiguar como está a situação desses laboratórios no contexto escolar, pois a existência desse espaço não aponta a utilização adequada ou a eficiência no contexto escolar; ou ainda, não está relacionada a com excelência em educação. Com isso, surge a nossa preocupação em relação ao funcionamento, reposição de materiais, limitação para o desenvolvimento de atividades e atuação dos professores nesses espaços escolares.

$\mathrm{Na}$ presente pesquisa, nos lançamos a analisar aspectos da implantação e do uso dos LMD em escolas localizadas em sete municípios na região Oeste do Estado do Pará, com o objetivo de investigar a situação dos laboratórios multidisciplinares na visão dos professores lotados nesse espaço pedagógico. Para a aproximação com esse objetivo, elaboramos questões de pesquisa, as quais se encontram na seção metodológica. Para subsidiarmos as analises, apresentamos a seguir as tendências do uso dos laboratórios no ensino de Ciências da Natureza.

\section{LABORATÓRIOS ESCOLARES E A EXPERIMENTAÇÃO}

Ao realizar um levantamento a respeito de pesquisas realizadas sobre - laboratório de Ciências, percebemos diversos problemas associados ao uso e, consequentemente, aos objetivos desses espaços no contexto escolar.

Um aspecto apontado por Freitas et al. (2013) é a falta de segurança nos laboratórios, no que diz respeito aos materiais de proteção individual (EPI), ao armazenamento e ao acondicionamento de reagentes químicos de 
forma incorreta, negligenciando normas básicas que oferece riscos à saúde. Em relação a esses reagentes, é necessário que seja firmado convênio com as universidades para 0 tratamento e 0 descarte dos reagentes que oferecem riscos à saúde.

Outro fator importante é a falta de investimento para a manutenção desses laboratórios, pois todo e qualquer material que é danificado possui dificuldade para ser reparado ou reposto, o que denota a falta de investimento dos órgãos públicos.

Vários autores (ANDRADE; COSTA, 2016; PEREIRA; MANDACARI, 2018; FREITAS, RIGOLON; BONTEMPO, 2013; PEREIRA; VITURINO; ASSIS, 2017) ressaltam que somente a existência do laboratório no contexto escolar não garante a melhoria do ensino de ciência; nem a realização de aulas experimentais, periodicamente, pois com a presença do laboratório outros problemas podem surgir se não forem bem gerenciados. Entre desses problemas estão: a carga excessiva de aulas, o grande número de estudantes por classe, a falta de materiais e a manutenção dos laboratórios, a falta de reconhecimento profissional, a falta de apoio da direção/coordenação. Vale ressaltar que a presença de um técnico no laboratório ajudaria a potencializar as atividades desenvolvidas nesse contexto, no entanto, outros problemas podem ser associados com a presença desse profissional, como aponta Pereira e Mandacari (2018) a respeito da formação específica desse profissional e o entendimento dele a respeito da função do laboratório didático nas escolas.

Conforme Kauark et al. (2017), quando o professor utiliza o laboratório escolar, a sua compreensão de como realizar as atividades está relacionada com as vivências e experiências que teve na universidade. Dessa forma, a maneira pela qual deve ser conduzida a atividade experimental no ensino de Ciências da Natureza, dentro ou fora do laboratório, dependerá muito da compreensão do professor sobre o objetivo do experimento e qual o entendimento sobre a natureza da Ciência.

O Laboratório de Ciências, no contexto escolar, pode ser considerado como qualquer espaço físico que difere da sala de aula convencional, pois 
possui diversos materiais, entre eles, equipamentos, materiais instrumentais, vidrarias e reagentes que requerem cuidado $e$ segurança no desenvolvimento da atividade.

O termo "laboratório" ganha uma dimensão ampla, pois, não é necessária uma sala com equipamentos, reagentes e vidrarias para chamarmos de laboratório. Entendemos que o termo se estende para qualquer espaço que visa a investigar a construção do conhecimento científico em qualquer área. Conforme Berezuk e Inada:

Vale ressaltar que o sentido de laboratório, pode ser qualquer espaço físico que seja destinado as atividades experimentais, pois, "é possível, de acordo com a realidade de cada escola que o professor realize adaptações nas suas aulas práticas a partir do material existente e, ainda, utilize materiais de baixo custo e de fácil acesso" (BEREZUK; INADA, 2010, 207p).

Os laboratórios científicos de centros de pesquisa e universidades são conduzidos para explorar fenômenos físicos, químicos ou biológicos com o objetivo de desenvolver teorias. Já no contexto escolar, os laboratórios didáticos ou laboratórios multidisciplinares possuem uma série de funções pedagógicas, dentre elas, ensinar Ciências, ensinar sobre a Ciência e ensinar como fazer Ciência.

Nesse contexto, Hodson (1988) defende que o objetivo do laboratório didático pode ter variados objetivos, entre eles, demonstração de um fenômeno, ilustração da teoria, teste de hipótese, construção do método científico, manipulação de vidrarias e reagentes, a comprovação da teoria, entre outros.

Nessa dimensão, o objetivo do laboratório no contexto escolar não enfatiza somente a manipulação de materiais e equipamentos, mas sim o envolvimento no processo de aprendizagem na busca de formulação de hipóteses para problemas e soluções colocadas para os estudantes. É essencial que esses desafios envolvam atividades experimentais que levem os estudantes a refletirem a respeito do contexto social que estão inseridos, 
contribuindo para problematizar o conhecimento científico e desmistificar as percepções sobre a ciência.

No ensino de Ciências alguns autores (ALVES FILHO, 2000; BORGES, 2002, PEREIRA; VITURINO; ASSIS, 2017) classificam as atividades experimentais em categorias que podem ser trabalhadas, tais como, demonstração, verificação, ilustração e investigação. Na demonstração ou ilustração, de forma geral, o professor conduz a atividade de tal maneira que os estudantes irão observar os fenômenos; com isso se torna essencial que o professor problematize-os fenômenos. Já na atividade de verificação, o estudante irá realizar a atividade de forma a comprovar a teoria; essa forma de conduzir a atividade no laboratório é muito utilizada nos componentes curriculares das universidades.

No que se diz respeito às atividades investigativas, Tamir (1990) aponta que muitas interpretações sobre as atividades experimentais que possuem o viés de investigação apresentam uma abordagem diferentes das convencionais, pois nessas o contexto (problema, objetivo e procedimentos) são estabelecidos pelo professor, ficando ao estudante a função de coletar os dados e, com o auxílio do professor, tirar possíveis conclusões.

Esse autor apresenta uma classificação de atividades práticas em diversos graus de complexidade. No nível 0 , as atividades são orientadas pelo professor, ou seja, o professor fornece aos estudantes, o problema a ser investigado, assim como os roteiros experimentais e as conclusões que se espera. No nível 1, o professor pode fornecer o problema e o roteiro, porém, agora cabe aos estudantes elaborar as conclusões. No nível 2, o professor fornece o problema e os estudantes podem elaborar os procedimentos da atividade investigativa e elaborar as conclusões. No nível 3, o problema, o procedimento e a conclusão são realizados pelos estudantes. Nesse sentido, conforme aumenta a autonomia dos estudantes durante as atividades experimentais, aumenta o nível de investigação.

A nosso ver, o objetivo do laboratório de ciências com viés pedagógico é promover e articular o ensino com o currículo escolar de formar a criar um campo de aprendizagem que permita aos estudantes 
compreenderem o processo do conhecimento científico para, a partir dele, refletir sobre situações vivenciadas pela sociedade. Este objetivo pode levar - estudante para além da racionalidade científica e da aparente neutralidade da ciência, ao percebe que a atividade científica está relacionada a diversos setores da sociedade.

Partindo desse contexto teórico, é essencial ressignificar a importância do laboratório enquanto espaço potencial para auxiliar na construção do conhecimento científico e da formação para a cidadania.

\section{ABORDAGEM METODOLÓGICA}

\section{Situando a pesquisa}

Analisamos a implantação e o uso de LMD em vinte e três escolas estaduais localizadas em cinco municípios na região Oeste do Estado do Pará. O objeto de estudo são os processos da implantação dos LMD, as diretrizes de uso desses nas escolas pelos professores, os procedimentos e as dificuldades da utilização dos laboratórios, assim como a articulação dos procedimentos dos professores com as respectivas formações básicas.

Os laboratórios multidisciplinares (LMD) de Ciências, das escolas estaduais da região Oeste do Pará, são os objetos de estudo dessa pesquisa. A investigação foi realizada a partir das entrevistas com professores lotados nos laboratório e/ou diretores das escolas localizadas nas cidades apresentadas na figura 01.

Os autores desta pesquisa iniciaram a atividade por meio de um projeto de iniciação científica que objetivava investigar os LMD da cidade de Santarém e, a partir disso realizar um diagnóstico da situação desses espaços didáticos.

Nas demais cidades investigadas, ocorreu a participação de licenciandos dos cursos Biologia e Química do Plano Nacional de Formação de Professores (PARFOR), que realizaram a pesquisa em conjunto com o primeiro autor deste trabalho. 
FIGURA 01 - Municípios do Oeste do Pará investigados

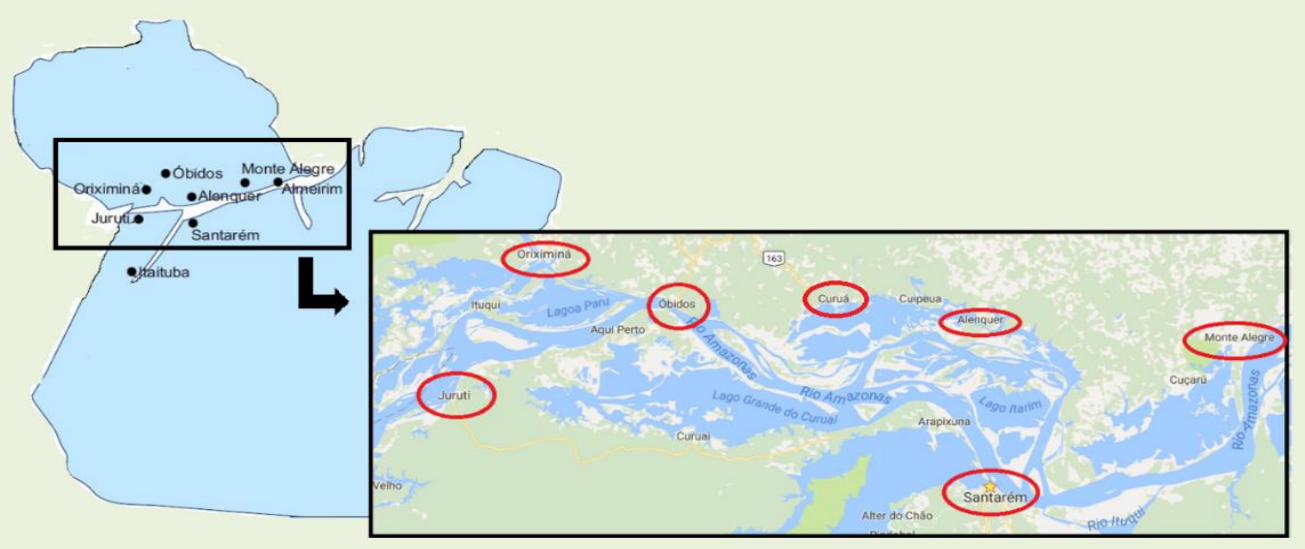

Fonte: Google mapas 2017 - adaptado.

A construção dos dados se deu entre os anos de 2012 e 2016. Consideramos um período longo, mas que se justifica pela distância e difícil acesso entre as cidades.

\section{A construção dos dados e o perfil da pesquisa}

O corpus da pesquisa foi constituído a partir de entrevista realizada com vinte professores, dos quais quatorze participavam da organização do espaço e seis apenas atuavam durante suas aulas.

As entrevistas versaram três perspectivas: aspectos físicos e materiais disponíveis no LMD; a formação do professor que atua no LMD; a atuação do professor no LMD.

Utilizamos a técnica de entrevista semipadronizada, pertencente à modalidade de entrevista semiestruturada. Na entrevista semipadronizada, o entrevistado é submetido a perguntas abertas.

Para realizar a entrevista semipadronizada, o entrevistador poderá dispor de tópicos guia ou lembretes, indicando uma agenda a seguir (GIL, 2003). Na presente pesquisa, elaboramos um guia de questões apresentadas na próxima seção. Para a elaboração e a interpretação dos dados, mobilizamos os referenciais teóricos citados nas discussões, bem como nas seções anteriores. 
Pelos procedimentos seguidos na construção e interpretação dos dados, classificamos a pesquisa como sendo de natureza qualitativa, que explora todos os processos e suas articulações (BOGDAN; BIKLEN, 2010).

\section{As questões de pesquisa e a organização dos dados}

Focamos na participação dos professores para a implantação dos LMD, nas suas estruturas Físicas, o papel que o LMD tem exercido no contexto escolar, as atividades nele desenvolvidas e as relações das orientações dessas atividades com a formação dos professores.

Para contemplarmos o intento anterior, elaboramos as questões de pesquisa a seguir, as quais conduziram as perguntas aos respondentes:

1) Qual a estrutura Física, os bens patrimoniais, os materiais didáticos e os experimentos disponíveis, bem como as condições de usos dos LMDs?

2) Como são desenvolvidas as atividades nos LMDs e as possíveis relações dessas com as formações dos professores?

3) Quais são os principais enfrentamentos apontados pelos professores designados aos espaços dos LMDs?

Estabelecemos categorias, a priori, para organizarmos os dados construídos.

São elas: 1. Mapeamento dos LMDs no Oeste do Pará; 2. A estrutura dos LMDs; 3. As atividades experimentais desenvolvidas nos LMDs; e 4. As indicações dos professores para a otimização dos LMDs.

\section{O ENREDO CONTEXTUAL DOS LMDs: análise e discussão}

É importante salientar que, na busca para organizar e discutir os dados construídos, adotamos as questões de investigação como guia, as quais foram elencadas anteriormente. No entanto, as indicações consequentes não podem ser generalizadas para todas as situações, haja vista as especificidades do contexto.

Acreditamos que as discussões apontadas podem prestar-se como subsídio para reflexão envolvendo futuras tomadas de decisões acerca da 
implantação e uso de LMDs, tanto no contexto da realização da pesquisa, quanto em outras localidades do Brasil.

\section{Mapeamento dos laboratórios Multidisciplinares.}

Considerando os caminhos metodológicos para realização desta pesquisa, os resultados serão apresentados por municípios, na seguinte sequência: Santarém, Alenquer, Curuá, Óbidos, Oriximiná, Monte Alegre e Juruti.

É importante ressaltar que os dados construídos ao longo dessa pesquisa abrangeram o período entre 2012 e 2016, devido a distância entre as cidades. Com isso os resultados em número expressos, podem diferir da realidade atual, por exemplo, uma escola que não tinha professor lotado no LMD, pode ter na atualidade, um espaço que não funcionava na época da pesquisa, pode hoje já estar em funcionamento.

Conforme o quadro 01 , foram visitadas um total de 26 escolas na região Oeste do Pará, o que não corresponde ao total de laboratórios existentes na região.

QUADRO 01 - Relação de municípios e escolas visitadas

\begin{tabular}{|c|c|c|c|c|c|c|}
\hline Município & $\begin{array}{c}\text { Quantidade de } \\
\text { escolas } \\
\text { visitadas }\end{array}$ & $\%$ & $\begin{array}{c}\text { Professores } \\
\text { lotados no LMD } \\
\text { entrevistados }\end{array}$ & $\%$ & $\begin{array}{c}\text { Corpo técnico } \\
\text { (diretor) } \\
\text { entrevistado }\end{array}$ & $\%$ \\
\hline Santarém & 14 & $54 \%$ & 14 & $78 \%$ & 0 & $0 \%$ \\
\hline Alenquer & 3 & $12 \%$ & 1 & $6 \%$ & 2 & $33 \%$ \\
\hline Curuá & 1 & $4 \%$ & 1 & $6 \%$ & 0 & $0 \%$ \\
\hline Óbidos & 1 & $4 \%$ & 0 & $0 \%$ & 0 & $0 \%$ \\
\hline Oriximiná & 2 & $8 \%$ & 1 & $6 \%$ & 1 & $17 \%$ \\
\hline $\begin{array}{c}\text { Monte } \\
\text { Alegre }\end{array}$ & 2 & $8 \%$ & 1 & $6 \%$ & 0 & $0 \%$ \\
\hline Juruti & 3 & $12 \%$ & 0 & $0 \%$ & 3 & $50 \%$ \\
\hline Total & 26 & $100 \%$ & 18 & $100 \%$ & 6 & $100 \%$ \\
\hline
\end{tabular}

Fonte: Os autores.

As escolas visitadas correspondem ao total de 24, distribuídas nas cidades de Santarém (14) 58\%, Alenquer (3) 13\%, Curuá (1) 4\%, Óbidos (1) 4\%, 
Oriximiná (2) $8 \%$, Monte Alegre (2) $8 \%$ e Juruti (1) 4\%. Vale ressaltar que Juruti não possuía LMD.

Com isso, Santarém se destaca com o maior número de escolas públicas que possuem LMDs - vale lembrar que a população estimada pelo Instituo Brasileiro de Geografia e Estatística (IBGE) em 2018 foi de 302.667 habitantes. As escolas que possuem LMD estão localizadas na região central da cidade.

De acordo com o IBGE, Santarém possui 40 escolas com Ensino Médio, com 778 docentes atuantes nesse nível de ensino, logo, o total de 14 escolas com laboratório corresponde a $35 \%$ o universo investigado. Conforme o quadro 01, foram entrevistados 14 professores, ou seja, um professor por escola, que possuíam formação em Biologia, Química, Física ou Matemática que atuam como professor do LMD. O número de estudantes matriculados nesse nível de ensino foi de 15.568, conforme os dados do IBGE para 2017.

Já em Alenquer, a população estimada pelo IBGE em 2018 foi de 56.480 habitantes. O total de docentes que atuavam nas três escolas de Ensino Médio era 69. Conforme dados do IBGE para o ano de 2017, foram realizadas 2.692 matrículas no Ensino Médio. As três escolas possuíam LMD, no entanto, somente um professor, lotado nesse espaço, foi entrevistado. Nas outras escolas, foi entrevistado um professor de sala de aula e um diretor da escola.

Em Curuá, a população estimada pelo IBGE em 2018 foi de 14.197 habitantes. Somente uma escola possuía Ensino Médio, conforme os dados de 2017, esta informação corresponde à escola investigada nessa pesquisa. O número de estudantes matriculados nesse nível de ensino foi de 763 estudantes e 21 docentes atuantes no Ensino Médio em 2017.

Óbidos possui uma população de 51.964 habitantes, com 3 escolas de Ensino Médio, 528 docentes atuantes nessas escolas e somente uma escola possuía, na época da pesquisa, laboratório multidisciplinar, nessa escola entrevistamos o professor lotado no espaço escolar.

O município de Oriximiná possui 72.160 habitantes conforme O IBGE, 6 escolas oferecem 0 Ensino Médio, com cerca de 3.064 estudantes 
matriculados e atuam 119 docentes nesse nível de ensino. O universo investigado e que possui o LMD foi 2 escolas correspondente a $33 \%$ das escolas do município. Foram entrevistados um professor que atuava nesse espaço e dois diretores e/ou coordenadores pedagógicos que atuavam nas outras duas escolas.

O município de Monte Alegre possui cerca de 57.900 habitantes, 7 escolas estaduais com 126 docentes atuando nesse nível de ensino e 3.462 estudantes matriculados no Ensino Médio. Desse universo foram investigadas duas escolas que possuem o LMD e uma professora que atua nas duas escolas.

Visitamos o município de Juruti que possui uma população de 56.908 habitantes, quatro escolas com Ensino Médio, 55 docentes atuantes e 2.302 estudantes matriculados nesse nível de ensino. As visitas foram realizadas e promovemos reuniões com os diretores e/ou coordenadores das escolas, pois as escolas não possuíam LMD.

\section{A estrutura Física e os materiais dos laboratórios didáticos}

Analisamos aqui a estrutura física, os bens patrimoniais e os experimentos didáticos disponíveis nos LMDs, assim como seu estado de conservação. Os dados foram construídos pelo entrevistador por meio de visitas in loco aos LMDs, complementados pelas entrevistas com os professores atuantes no espaço. Buscamos responder à seguinte questão de pesquisa: Qual a estrutura Física, os bens patrimoniais, os materiais didáticos e os experimentos disponíveis, bem como as condições de usos dos LMDs?

Os LMDs possuem um padrão de estrutura Física bastante semelhante, haja vista terem sido construídos a partir de ações do mesmo projeto. Uma estrutura presente em todos os LMDs são as bancadas centrais, dispostas paralelamente, com duas pias em cada e torneiras. Alguns possuem duas e seis bancadas.

Alguns LMDs possuem bancadas laterais com armários na parte inferior, onde acomodam materiais, outros dispõem de armário metálico, nos quais acondicionam reagentes. 
Alguns espaços foram construídos, exclusivamente, para funcionarem como LMDs, outros foram adaptados de salas de aula já construídas para o funcionamento como laboratório. De certa forma, todos os laboratórios possuem espaço amplos, com capacidade para 30 estudantes, no entanto, consideramos ainda esse número muito alto, pois o laboratório é um local que requer cuidado e segurança.

Verificamos a presença de alguns defeitos como paredes rachadas, pias com mau funcionamento, lâmpadas queimadas, dutos com vazamento, torneiras danificadas, outros laboratórios não possuem água encanada, situações presentes em $30 \%$ dos laboratórios visitados. No interior de vários laboratórios existe um banheiro, porém, nem todos em funcionamento, por essa razão alguns funcionam como depósito de materiais.

No tocante a bens patrimoniais, três laboratórios dispõem de aparelhos de TV. Vários laboratórios (70\%) dispõem de um computador, porém nem todos estão conectados à rede de internet, além de apresentarem mau funcionamento. Alguns laboratórios (50\%) possuem geladeira e arcondicionado

A Figura 02 apresenta um esquema geral dos LMDs contendo (a) pias; (b) bancadas centrais; (c) bancada lateral com armários embutidos; (d) armários de aço com equipamentos; (e) quadro branco; (f) sala auxiliar ou expurgo; e (g) chuveiro. As dimensões de cara item apresentado diferem em cada escola.

FIGURA 02 - Estrutura básica do laboratório multidisciplinar

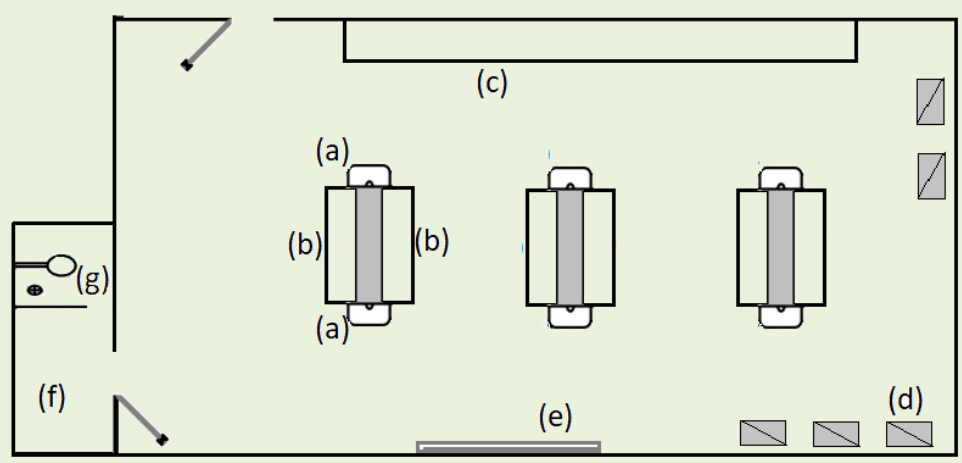

Fonte: Os autores. 
Conforme mencionado, faz parte da implantação dos LMDs a disponibilização de kits das áreas de Química, Física, Biologia e Matemática. Apesar do foco dos laboratórios, o material disponibilizado ainda segue o mesmo padrão doutros momentos históricos, com isso vale ressaltar que a atividade experimental não deve ser encarada apenas como estratégias complementar de ensino (CAVALVANTI; QUEIRÓS, 2018).

O kit de Química é constituído por algumas vidrarias e reagentes ${ }^{4}$. Muitos desses se encontram com validade vencida (30\%), se decompondo em subprodutos. No entanto, vale ressaltar que os reagentes presentes podem ser utilizados mesmo que vencidos, ou seja, vencidos ou não, os reagentes que se encontravam naqueles laboratórios poderiam ser utilizados para aulas experimentais. Alguns reagentes presentes, como hidróxido de sódio são higroscópico - absorve água do ambiente - e gera subprodutos que os invalida para a atividade experimental. É importante ressaltar que os LMDs não possuíam informativos a respeito das características físicas e químicas de cada reagente.

Complementando a perspectiva anterior, alguns professores desconhecem as informações sobre o manuseio correto dos reagentes (21 $\%)$. Inclusive devido a esse desconhecimento, alguns professores não manuseavam reagentes químicos.

O kit de Física possuía equipamentos variados, contemplando o conteúdo de Física Clássica. Uma parcela dos professores (15\%) consideraram o kit complexo e inadequado para trabalhar os conceitos de Física apresentado no referencial curricular adotado. Tanto que, em três laboratórios, os materiais aparentavam nunca terem sido utilizados.

O kit de Biologia continha modelos didáticos, tais como, corpo humano e esqueleto humano didáticos, microscópio ótico, etc. No entanto, vários desses necessitam de reposição de peças, haja vista que se encontram danificados pelo extravio de peças.

$4 \mathrm{Em}$ sua maioria são de sais, como $\mathrm{NaCl}, \mathrm{KCl}, \mathrm{Na}_{2} \mathrm{SO}_{4}$, base, como $\mathrm{KOH}$ e $\mathrm{NaOH}$, bem como ácidos, como $\mathrm{HCl}$ e $\mathrm{H}_{3} \mathrm{PO}_{4}$ 
O extravio de peças era bastante acentuado nos objetos didáticos de alguns laboratórios, talvez, pelo fato de, especificamente, em algumas escolas esse espaço funcionar somente em um período como LMD e como sala de aula comum nos demais horários. Tal fato aumenta o fluxo de aluno no espaço.

Em dois laboratórios visitados, os kits de experimentação ainda estavam encaixotados, isso evidencia que a implantação do espaço não estava de acordo com as intenções iniciais do Projeto Alvorada, ou ainda, que não foi incentivado e fornecido suporte para que esses materiais fossem postos em funcionamento.

Outra constatação nos espaços dos laboratórios foi a ausência de equipamentos de segurança, tais como extintores de incêndio. Apenas em um laboratório que o extintor foi identificado, porém, com prazo de validade vencido.

Em relação a utilização do espaço dos laboratórios, constatamos que algumas escolas desenvolviam atividades que auxiliavam as demais disciplinas, por exemplo, a realização de projetos integrados. No entanto, muitas vezes não estavam associados a utilização de atividades experimentais em ciências; por exemplo, o uso do LMD como sala de vídeo. Em outras escolas o espaço era utilizado como biblioteca, pois não havia esse espaço de pesquisa na escola.

Existe a necessidade de entender que o laboratório é um espaço potencial para o processo de ensino e aprendizagem, tanto como a sala de aula. Se isso não acontecer, esse espaço poderá ser desvalorizado e pouco utilizado, até chegar ao ponto do obsoletismo ou ser readequado para o desenvolvimento de outras atividades. Uma oportunidade de contornar tal situação é elaboração de projetos, com vista à formação continuada de professores para atuarem neste espaço de forma interdisciplinar.

É importante apontarmos que em todas as escolas investigadas a relação entre diretores, professores de sala de aula e professores de laboratório se dá de forma harmoniosa. 


\section{As formações dos professores e as ações nos laboratórios}

Nessa atividade de investigação um dos intentos foi relacionar as atividades desenvolvidas nos LMDs pelos professores com as respectivas formações, diante das singularidades que emergem do contexto.

Preliminarmente, apresentamos no Quadro 02 as formações dos professores designados aos LMDs ou que utilizavam o espaço e participaram da pesquisa. Em seguida, aproximamos essas das respectivas ações e interações manifestas.

QUADRO 02 - Formação dos professores entrevistados

\begin{tabular}{|c|c|c|c|c|}
\hline $\begin{array}{c}\text { Formação } \\
\text { Básica }\end{array}$ & $\begin{array}{c}\text { Ciências } \\
\text { Naturais }\end{array}$ & Física & Biologia & Química \\
\hline Professores & $8 \%$ & $8 \%$ & $63 \%$ & $21 \%$ \\
\hline
\end{tabular}

Fonte: Os autores.

Todos os professores do município de Santarém, 54\% do total de pesquisados, estavam designados aos LMDs, cumprindo metade da carga horária das suas atividades e o tempo restante era desenvolvido com suas respectivas disciplinas em sala de aula.

Quanto ao viés das atividades experimentais, os professores mencionaram que a maioria das atividades desenvolvidas nos LMDs é de caráter demonstrativo, $71 \%$ com os estudantes tendo participado, previamente, das abordagens teóricas nas respectivas salas de aula, as quais foram desenvolvidas por outros professores.

A perspectiva demonstrativa para o uso do experimento é considerada eficaz para que o professor possa explicar uma dada atividade experimental em um quantitativo maior de estudantes. As aulas demonstrativas possuem dentre outras vantagens a economia de reagentes, além disso, possibilitam um controle quase que absoluto da atividade pelo professor; nesse sentido pode ser decidido o que evidenciar e qual sequência de ensino a ser abordada. As atividades experimentais demonstrativas também podem ser problematizadas, desde que os 
professores enfatizem as situações de investigação nos experimentos expostos.

Alguns professores, $21 \%$, justificaram a ênfase na demonstração devido à indisponibilidade de material didático para se trabalhar em outra perspectiva. Os kits disponíveis são únicos em cada área, para atender à demanda dos estudantes. A demonstração surge, nesse cenário, como maneira de economia de reagentes, pois existe a impossibilidade de reposição de material.

Certamente, não poderemos descartar a possibilidade de que, o predomínio dos experimentos didáticos em uma perspectiva demonstrativa pelos professores, que estes tenham consciência ou não dessa, deva-se a lacunas teóricas existentes nos próprios processos formativos. Alguns dos professores designados aos LMDs (33\%) realizaram cursos complementares relacionados com o uso dos laboratórios didáticos, propiciado pelos convênios firmados entre a Secretaria de Educação e outras instituições. Mesmo assim, mencionaram que não se sentiam confiantes para desenvolverem atividades experimentais na Educação Básica. Apesar da condição, os professores denotam empenharem-se para que os espaços funcionem efetivamente.

Tal constatação requer uma reflexão mais abrangente, haja vista que todos os entrevistados são licenciados na área de ciências da natureza, e mencionaram, explicitamente, que em seus processos formativos não foram contemplados com abordagens para atuarem nos laboratórios didáticos da Educação Básica. Inclusive, alguns apontam que as atividades de experimentação que realizaram durante o período foram, exclusivamente, para atender a demandas de componentes curriculares das áreas das ciências, as quais cursavam; ou seja, não tiveram nenhum componente curricular com experimentação problematizadora para a Educação Básica.

Vale ressaltar que o princípio da experimentação para o cientista é, entre outras, a busca de confirmação e investigação; já na Educação Básica, a experimentação é uma ferramenta pedagógica valiosa para estimular o conhecimento do estudante (HODSON, 1988). 
Em nenhuma etapa da formação básica os professores entrevistados tiveram abordagens teóricas sobre possibilidades e limitações da experimentação didática em abordagem para a Educação Básica. Não relataram a realização de experimentos nos estágios docência, mas sim a discussão e a abordagem da ciência e a natureza da ciência na construção do conhecimento envolvido em determinada atividade experimental, os quais requerem outras perspectivas teóricas de abordagens da experimentação, como por exemplo, as abordagens investigativas.

Quanto ao caráter da abordagem experimental no laboratório, Pereira et al (2017) defendem o uso da experimentação investigativa, pois esse tipo de atividade, possui potencialidade para contribuir com a criação de um ambiente favorável à aprendizagem; já que os estudantes entram em contato direto com o problema a ser investiga. Nessa abordagem, a investigação sobre o fenômeno da natureza em estudo é conduzida a partir das indagações dos estudantes e professores, possibilitando a apresentação de modelos e argumentos que melhor potencializam uma compreensão mais efetiva e duradoura do fenômeno estudado (MOTTA et al, 2013).

De acordo com Moreira et al. (2017), o tipo de atividade experimental a ser executada pelo estudante, está de acordo com os pressupostos da construção do conhecimento científico. Os autores ainda apresentam que é consenso de professores que tais atividades não sejam, absolutamente, mecânicas e tenham abertura para o diálogo; caso contrário, poderá levar a uma concepção positivista do laboratório. Nesse sentido, uma atividade que tem sido utilizada no ensino de ciências é o aporte problematizador proposto por Francisco Jr e colaboradores (2008). Trata-se da experimentação problematizadora, sustentada pela teoria freireana. Nesta perspectiva, o professor deve "suscitar nos estudantes o espírito crítico a curiosidade, a não aceitação do conhecimento simplesmente transferido" (p. 35).

Nesse direcionamento Kuark et al. (2017) ressaltam a importância de conduzir a formação de professores em uma perspectiva de problematizar as a relação entre teoria com a prática de forma reflexiva. Dessa forma, os 
professores poderão ter oportunidades de refletir sobre temáticas problematizadoras no ensino de Ciências da Natureza.

A orientação problematizadora, seja mediada pela experimentação ou não, incorpora potencialidades para se discutir muito mais do que conceitos científicos, mas, sobre a ciência, o trabalho do cientista, como o seu trabalho se relaciona com aspectos da tecnologia e como influenciam na sociedade. As atividades realizadas podem possuir diversos objetivos, dentre eles, o de contribuir com a compreensão da visão sobre aa ciência de forma a desenvolver um olhar crítico sobre o trabalho do cientista (CAVALCANTI; QUEIROS, 2018).

Um fato que merece destaque é a formação dos professores, pois, a maioria possui formação somente em uma área, o que é normal e esperado. O problema que surge com isso é que um professor que é formado em Física que está lotado no laboratório tem dificuldades em auxiliar ou preparar uma aula de Biologia, por exemplo. O mesmo acontecerá, respectivamente, com uma professora do LMD que é formada em Química e irá auxiliar uma aula de Física. Nesse caso, 93\% dos professores, um número expressivo, indicou a necessidade de curso de formação específico para atuação no laboratório, no qual, esses profissionais possam discutir teorias e realizar atividades práticas das três áreas do conhecimento. Dessa forma, os experimentos básicos de Química, Física e Biologia, os professores do LMD poderão auxiliar com mais eficácia os professores de sala de aula, que desenvolvem atividades nesse espaço.

Reconhecemos que a existência do laboratório didático de ciências em uma escola é um espaço potencializador para a melhoria do ensino, porém, vários outros encaminhamentos deverão estar em sintonia, como a formação dos professores que deverá ter sido construída com uma perspectiva compatível, a exemplo do que está mencionado anteriormente.

Uma proposta que pode contornar esta situação é a realização de cursos de aprimoramento educacional, com caráter experimental interdisciplinar; que possa proporcionar para os profissionais designados aos 
LMDs o aprendizado de conceitos básicos e associá-los à experimentação das áreas de ciências da natureza.

\section{As indicações dos professores para a otimização dos LMDs}

Aqui, analisamos as indicações dos professores relacionadas às demandas para a otimização do funcionamento dos LMDs. Convergimos para responder a seguinte questão de pesquisa: Quais os principais enfrentamentos apontados pelos professores atuantes nos LMDs?

Para identificar as dificuldades e reivindicações dos professores em relação à otimização das atividades nos LMDs, buscamos entender o papel dos professores designados ao espaço. Uma das tarefas primordiais desse é atender às demandas de aulas experimentais das áreas de Química, Física e Biologia, como preparar atividades experimentais requeridas pelos professores que implementam as aulas teóricas.

Se necessário, o professor designado ao LMD poderá assessorar a realização das atividades experimentais, desde que domine o conteúdo curricular. Esta participação auxilia no dinamismo e na interação durante a aula. Ainda poderá auxiliar no acompanhamento dos grupos das atividades experimentais, proporcionando maior segurança aos estudantes.

Dentre outras funções atribuídas ao professor designado ao LMD, encontra-se a separação das vidrarias, preparação de soluções, montagem de equipamentos, pesquisa de atividades a serem realizadas nos LMD pelos demais professores. Também é o responsável pela organização do local, antes e após a realização das atividades experimentais. $40 \%$ dos professores dos LMDs relataram que pesquisam atividades de outras áreas de sua formação para auxiliarem os professores das outras disciplinas. Alguns chegam até a preparar um roteiro experimental de atividades.

A partir do lugar que ocupa, o professor designado ao LMD poderá atuar como um sujeito articulador de projetos integradores envolvendo várias áreas do conhecimento. Segundo os professores entrevistados, o uso dos LMDs não tem sido frequente. Alguns professores (29\%) inclusive creditam o pouco uso do espaço à ausência de incentivo da direção escolar. Porém, 
$14 \%$ dos professores mencionaram que as respectivas direções escolares incentivam os professores no tocante à utilização do espaço e, mesmo assim, o apelo não tem sido correspondido. Outros $14 \%$ dos professores acrescentaram que a direção da escola vai além, investe financeiramente na compra de alguns materiais. Os professores (29\%) mencionaram que os respectivos diretores também incentivam o uso dos LMDs. Outros fatores que levantamos e que merece ser refletido é a pouca carga horária que o professor de sala de aula possui para desenvolver um currículo extenso, a cobrança que sofrem a respeito do cumprimento das metas escolares, a quantidade de aprovações e reprovações e o atendimento as diversas demandas que a escola está sujeita.

Para que os LMDs sejam usados com mairo frequência, $21 \%$ dos professores sugerem que o uso do espaço seja incluído nos planejamentos pedagógicos dos professores, ou mesmo, elaborarem um modelo de gestão. Contrariando esta perspectiva, alguns outros professores, $21 \%$, sugerem que a direção deveria tornar uso do espaço obrigatório com inclusão no plano de ensino do professor.

No que se diz respeito às atividades experimentais realizadas nos LMDs, $72 \%$ indicaram que a frequência de utilização é baixíssima, $17 \%$ relataram que é baixa, $11 \%$ indicaram como moderada, nenhum professor indicou a frequência como alta ou altíssima. Consideramos frequência baixíssima como a periodicidade de utilização do LMD uma vez a cada duas semanas ou a inexistência de atividades por mais de dois meses. A frequência baixa como a periodicidade de uma vez por semana, moderada como duas vezes por semana, alta, três vezes por semana e altíssima todos os dias, independente do componente curricular trabalhado.

Outra sugestão citada pelos professores, $79 \%$, no sentido de tornar o espaço do LMD mais utilizado foi à reposição de materiais, assim como a oferta de cursos aos professores designados a atuarem nos espaços.

Alguns professores, 36\%, argumentaram que existe a resistência, por parte de outros profissionais, em utilizarem o laboratório. Nessas escolas, a direção tem utilizado um plano de gestão do laboratório, de forma que 
cada professor da área de ciências naturais utilize o espaço, periodicamente. Outro ponto destacado pelos professores é a desvalorização da função do profissional do LMD na própria escola, como comenta uma das professoras: "a impressão que temos é que nossos colegas pensam que quem vai atuar no laboratório, não quer atuar em sala de aula". Isso reflete um cenário complexo, no qual, a compreensão de alguns professores da escola é que o LMD não é, adequadamente, utilizado e quem é lotado nesse espaço pedagógico, não irá trabalhar. Se os espaços não estão sendo, adequadamente, utilizados esse tipo de pensamento irá se propagar e promover resistências dos demais professores da escola. Dessa forma existe a necessidade expandir a compreensão da importância do laboratório para todas as áreas do conhecimento dentro da escola. Com isso destacamos a necessidade de ressignificação da função e da importância dos LMDs nas escolas.

Houve também um apontamento de $57 \%$, dos professores para que sejam auxiliados por meio de uma coordenação na secretaria de educação; outros $36 \%$, apontam a necessidade de que seja disponibilizado um guia de atividades experimentais. A necessidade de um guia de experimentos, é devido ao fato de muitos professores possuírem apenas uma formação.

Nesses dois pontos citados acima, vale ressaltar a importância de uma coordenação na secretaria de educação que se responsabilize, diretamente, com as atividades desenvolvidas nesse espaço. Apontamos a necessidade de ouvir os profissionais que estão lotados nesses espaços para que, didaticamente, as atividades sejam potencializadas.

A falta de manutenção dos espaços dos LMDs foi uma problemática apontada por $50 \%$ dos professores. Ressaltaram que não havia manutenção ou reposição de materiais, equipamentos, vidrarias e modelos didáticos, pois ao longo dos anos, tais materiais são danificados pela manipulação dos estudantes ou mesmo os professores. Autores como Pereira e Mandacari (2018) reforçam a necessidade de professores reivindicarem por mais 
equipamentos e reposição e materiais para o uso dos laboratórios didáticos como alternativa às aulas de ciências, no contexto escolar brasileiro.

A realização de cursos de aperfeiçoamento docente que possam promover a interação com professores de outras escolas foi apontada por $60 \%$ do público investigado.

Um número significativo, $64 \%$, dos professores apontaram que há incentivo da direção da escola, porém fazia-se necessário o comprometimento dos professores em utilizarem o espaço. Um professor também ressaltou o incentivo da direção da escola, mas, mesmo assim, os professores de sua escola não buscavam o espaço com frequência; esse professor sugeriu a realização de reuniões pedagógicas para planejamento e atuação no laboratório.

Concordamos com Pereira e Mandacari (2018), que remetem o fato das atividades experimentais serem ressignificadas no contexto escolar, pois muitos professores e administradores escolares apresentam a compreensão de que a função da experimentação é, simplesmente, a comprovação da teoria.

No entanto, ao analisar esse cenário com profundidade, não devemos atribuir a situação dos laboratórios aos professores e diretores, pois, como fundamentado no início desse trabalho, os LMDs foi um projeto do governo federal, mas entendemos ser essencial que a manutenção e a promoção de atividades nesses espaços aconteçam por intermédio da secretaria de educação. Em outras palavras, indicamos a necessidade de políticas públicas que invistam nesses espaços para a valorização e a continuidade das atividades curriculares.

Vários professores entrevistados procederam com sugestões para a otimização dos espaços dos LMDs, as quais envolviam a Secretaria de Educação, representadas pelas UREs. Dentre essas, sugeriram que poderiam criar de uma coordenadoria com a finalidade de atender as solicitações dos professores designados aos LMDs. Também destacaram ser essencial que a URE corrobore com a realização de ações que fortaleça o desenvolvimento 
de atividades experimentais nas escolas. Destacaram com maior predominância, as ações a seguir:

1. Busca de parcerias: a realização de parcerias ou convênios com as universidades locais para promoverem cursos de formação de professores, visando à promoção de cursos de formação continuada e oficinas, relacionados à experimentação no campo da Biologia, Física e Química, com enfoques teóricos e práticos. Com isso, sugerimos o oferecimento de curso de complementação pedagógica para atuação no laboratório. Consideramos essa uma das mais importantes.

2. Gestão dos laboratórios: Criação de um setor na secretaria de educação, uma coordenadoria que se responsabilizasse, exclusivamente, pelas demandas dos laboratórios. Essa coordenadoria buscará fomentar a discussão para que o espaço seja reconhecido como potencialmente didático no auxílio da construção do conhecimento e formação para a cidadania.

3. Manutenção: reposição de materiais como vidrarias, reagentes e equipamentos, bem como reparos físicos em pias torneiras e outras demandas apontadas pelos professores. Aquisição de materiais adequados, entre eles, mesas armários, material de fundamentação teórica sobre experimentação no ensino de ciências.

4. Promoção de eventos e atividades de formação: a coordenadoria seria responsável pela promoção de eventos e atividades em conjuntas, como a socialização de atividades desenvolvidas nos LMDs.

5. Valorização do profissional: valorização do trabalho dos professores que atuam nesse espaço, de forma que eles sejam articuladores dos projetos desenvolvidos na escola. Além da articulação com as demais áreas do conhecimento, presente na escola.

6. Avaliação dos laboratórios: os materiais, reagentes e resíduos dispostos nos laboratórios, precisam ser avaliados e, conforme for o caso, encaminhar para descarte adequado.

7. Políticas públicas: é essencial que o corpo docente e administradores escolares, reivindiquem por melhoria das condições de 
trabalho perante a secretaria de educação, como forma de incentivar a criação de políticas públicas que valorizem esse espaço.

Vale ressaltar que não é culpa dos professores da escola e nem dos lotados nos laboratórios se esse espaço está sendo pouco utilizado. Temos que parar de colocar a culpa somente nos professores. Existe um sistema educacional que promoveu essa situação, o mesmo sistema que não deu continuidade às ideias iniciais do Projeto Alvorada, logo, nenhum projeto se sustenta se não possui investimento; e toda essa situação acaba culminando nas mãos dos professores lotados nesse espaço. Por isso a resistência de muitos professores em atuar nesses laboratórios, com isso existe a necessidade de repensar, readequar e ressignificar a função dos laboratórios de ciências no estado do Pará.

Pelas considerações anteriores, os professores parecem denotar não sentirem como sujeitos ativos no sentido de empreenderem mudanças na utilização do laboratório.

\section{CONSIDERAÇÕES FINAIS}

A pouca frequência de uso dos LMDs traz evidências de que a problemática converge para o campo formativo desses profissionais, haja vista que o tempo requerido para o planejamento e a elaboração das atividades está compartilhado. Deve-se, certamente, a ausência de uma percepção acerca das potencialidades didáticas do espaço. Outra evidência da estranheza dos LMDs nas escolas é a ausência de manutenção e reposição de alguns materiais, sobretudo aqueles com validade determinada, a ausência de um planejamento mais extenso e abrangente das atividades para esses espaços, bem como uma proposta teórica, conforme evidenciado em outra categoria. Apenas a implementação inicial dos LMDs não assegura o bom funcionamento das atividades a serem desenvolvidas.

No sentido de ressignificar os espaços dos LMDs no contexto da escola, bem como torná-lo um ambiente de pesquisa, os diretores e coordenadores escolares, por meio das UREs poderão promover articulações com projetos 
desenvolvidos pelas universidades, a exemplo do PIBID, PIBIC Jr, PIBIC, campos de estágios docência e outros. Além de mobilizarem a articulação da Educação Básica com a universidade, notadamente, para os licenciandos conhecerem a complexidade do seu campo de formação, tanto os professores escolares quanto os das universidades poderão ter nos LMDs um campo de pesquisa, haja vista que, neste contexto, a formação docente carece de inserção nesse campo.

$\mathrm{Na}$ perspectiva de utilização do LMD evidenciada no contexto investigado, percebemos que a gestão educacional, na esfera da elaboração e implementação da política educacional, concebe a experimentação didática como, prevalentemente, vinculada à prática das ciências da natureza. Assim, onde se encontra a pertinência da linguagem, da geografia, da história e até mesmo da Matemática na multidisciplinaridade do conhecimento?

Entendemos que os laboratórios multidisciplinares, pela sua natureza, são espaços com amplas possibilidades para se desenvolverem atividades com amplo potencial para corroborar com à construção de perspectivas teórico-metodológicas sobre as ciências, a partir das suas inter-relações, bem como adentrando em outras áreas, as quais não necessariamente, as ciências.

Outra necessidade é que aos professores que completaram suas respectivas formações básicas seja oportunizado a participação em programas de aperfeiçoamentos, no sentido de construírem outras perspectivas teóricas acerca dos experimentos didáticos. Tal perspectiva também chama a atenção dos formadores de professores.

Percebemos a escassez desse tipo de pesquisa na área de ensino de ciências no Brasil, por isso ressaltamos a necessidade de investigações para que possam contribuir no processo de criação políticas de valorização do LMD como espaço formativo. 


\section{REFERÊNCIAS}

ALVES FILHO, J. P. Regras da transposição didática aplicadas ao laboratório didático. Cad. Cat. Ens. Fís.,v.17, n.2 p.174-188, 2000.

ANDRADE, T. Y. I.; COSTA, M. B. O Laboratório de Ciências e a Realidade dos Docentes das Escolas Estaduais de São Carlos-SP. Revista Química Nova na Escola, v. 38, n. 3, p. 208-214, 2016.

BEREZUK, P. A.; INADA, P. Avaliação dos laboratórios de ciências e Biologia das escolas públicas e particulares de Maringá, Estado do Paraná. Acta Scientiarum. Human and Social Sciences. Maringá, v. 32, n. 2, p. 207-215, 2010.

BOGDAN, R. C.; BIKLEN, S. K. Características da investigação qualitativa. In: Investigação qualitativa em educação: uma introdução à teoria e aos métodos. Porto, Porto Editora, 2010.

BORGES, A. T. Novos rumos para o laboratório escolar de ciências. Caderno Brasileiro de Ensino de Física, v. 19, n.3, p. 291-313, 2002.

BRASIL. Ministério da Educação. Notas Estatísticas Censo Escolar 2017, Janeiro de 2018. Disponível em

http://download.inep.gov.br/educacao_basica/censo_escolar/notas_estatist icas/2018/notas_estatisticas_Censo_Escolar_2017.pdf. Acesso em 25 de jun. de 2018.

CAVALCANTI, K. M. P. H.; QUEIROS, G. R. P. C.; Laboratório didático de química e o ensino médio integrado à educação profissional. Revista educação química: em punta de vista, v. 2, n. 2, 2018.

FREITAS, F. V.; RIGOLON, R. G.; BONTEMPO, G. C. Avaliação e diagnóstico dos laboratórios didáticos das escolas públicas de Viçosa/MG. Anais do IX

Encontro Nacional de Pesquisa em Educação em Ciências - IX ENPEC Águas de Lindóia, SP - 10 a 14 de Novembro de 2013.

FRANCISCO JÚNIOR, W. FERREIRA, L. H. HARTWIG, D. R. Experimentação Problematizadora: Fundamentos Teóricos e Práticos para a Aplicação em Salas de Aula de Ciências. Química nova na escola, N. 30, 2008.

HODSON, D. Experiment in The Science Education. Educational Philosophy and Theory, 20, $53-66,1988$.

KAUARK, F. S.; GONÇALVES, N. T. L P.; COMARÚ, M. W. Importância, Características e Atividades dos Laboratórios de Ensino de Ciências. Anais do XI Encontro Nacional de Pesquisa em Educação em Ciências - XI ENPEC Universidade Federal de Santa Catarina, Florianópolis, SC - 3 a 6 de julho de 2017. 
MAPS/BRASIL - Ministério da Assistência e Promoção Social. Projeto Alvorada. Disponível em http://www.mds.gov.br/relcrys/alvorada/apresentacao.htm\# 1 Acesso em 27/12/2016.

MENEZES, E. T.; SANTOS, T. H. Verbete Projeto Alvorada. Dicionário Interativo da Educação Brasileira - Educabrasil. São Paulo: Midiamix, 2001. Disponível em: <http://www.educabrasil.com.br/projeto-alvorada/>. Acesso em: 30 de dez. 2018.

MOREIRA, M. C. A.; LOPES, F. P. KAUARK, F. S.; GONÇALVES, N. T. L P.; COMARÚ, M. W. Os termos "atividade de laboratório", "atividade experimental" e "atividade prática" nos enunciados de mestrandos em ensino de ciências. Anais do XI Encontro Nacional de Pesquisa em Educação em Ciências - XI ENPEC, Florianópolis, SC - 3 a 6 de julho de 2017.

MOTTA, C. S., DORNELES, A. M., HECKLER, V., GALIAZZI, M. C. Experimentação Investigativa: indagação dialógica do objeto aperfeiçoável. IX Encontro de Pesquisa em Educação em Ciências, Anais, Águas de Lindóia, São Paulo: SP, 10 a 14 nov. 2013.

PAIXÃO, N. C. G.; PEREIRA, A. S. Dificuldades apresentadas por professores lotados em laboratórios multidisciplinares na cidade de Santarém-PA. Anais Anais/Resumos da Reunião Regional da SBPC. Oriximiná/PA, novembro,2012.

PEREIRA, A. S.; VITURINO, J. P.; ASSIS, A. O uso de indicadores naturais para abordar a experimentação investigativa problematizadora em aulas de Química. Educação Química en Punto de Vista, v. 1, p. 135-148, 2017.

PEREIRA, A. S.; MANDACARI, C. Um estudo sobre as condições estruturais e materiais dos laboratórios didáticos de ciências das escolas públicas de Dourados/MS. Actio: Docência em Ciências, v. 3, p. 1-17, 2018.

SEDUC/PA. Portaria 023/2011 de 11 de abril de 2011. Dispõe sobre critérios a serem adotados para lotação de pessoal nas Unidades Administrativas e Escolares da Secretaria de Estado de Educação Belém, 11 abr. 2011. Disponível em https://ntetucurui.files.wordpress.com/2009/11/portaria-delotac3a7c3a3o2011.doc. Acesso em 25 de abr. de 2016.

SEDUC/PA. Instrução Normativa n. 3 de 1 de março de 2016. Dispõe sobre critérios a serem adotados para lotação de pessoal nas Unidades Administrativas e Escolares da Secretaria de Estado de Educação. Belém, 07 mar. 2016. Seção 1, p.21-26. Disponível em https://www.sistemas.pa.gov.br/sisleis/legislacao/3023. Acesso em 25 de abr. de 2016. 